\title{
Pemanfaatan Media Sosial Tiktok Sebagai Media Promosi Industri Kuliner Di Yogyakarta Pada Masa Pandemi Covid-19 (Studi Kasus Akun TikTok Javafoodie)
}

\author{
Chriswardana Bayu Dewa'), Lina Ayu Safitri²) \\ Sistem Informasi, Fakultas Teknik dan Informatika, Universitas Bina Sarana Informatika ${ }^{1,2)}$ \\ Jl. Ringroad Barat, Ambarketawang, Gamping Sleman, Yogyakarta 55184 \\ E-mail : chriswardana.chb@bsi.ac.id ${ }^{1)}$
}

\begin{abstract}
Abstrak
Pada masa pandemi Covid-19, banyak sekali pelaku usaha kuliner yang mengalami penurunan pendapatan usaha terutama di daerah wisata seperti Yogyakarta. Hal tersebut membuat para pengusaha kuliner mencari jalan keluar untuk tetap memperoleh pendapatan. Salah satu usaha yang dapat dilakukan adalah melakukan promosi produknya melalui media sosial. Saat ini platform media sosial yang populer adalah Tiktok. Total unduhan aplikasi Tiktok pada tahun 2020 sebanyak 63,3 juta kali dan Indonesia menjadi negara yang paling banyak mengunduh aplikasi tersebut sebesar $11 \%$ dari total unduhan aplikasi Tiktok. Berdasarkan fakta tersebut, aplikasi Tiktok berpeluang menjadi media promosi yang efektif dalam memasarkan industri kuliner khususnya di Daerah Istimewa Yogyakarta. Salah satu akun Tiktok yang mempromosikan industri kuliner di Daerah Istimewa Yogyakarta adalah Javafoodie. Akun Javafoodie mempromosikan industri kuliner dengan metode yang unik yaitu story telling dengan nuansa komedi, sehingga diharapkan dapat menarik minat beli konsumen.Tujuan dari penelitian ini adalah untuk mengetahui faktor-faktor apa yang menjadikan Tiktok sebagai media promosi yang efektif pada masa pandemi Covid-19. Peneliti menarik kesimpulan bahwa Tiktok menjadi media promosi yang efektif karena Tiktok memiliki banyak pengguna, mudah digunakan, populer di kalangan milenial, sering digunakan oleh selebriti dan memiliki fitur Tiktok ads yang dapat mengoptimalkan penyebaran konten.
\end{abstract}

Kata Kunci : Media Sosial, Promosi, Tiktok

\section{The Utilization Of Tiktok Social Media As A Media For Culinary Industry Promotion In Yogyakarta In The Pandemic Time Of Covid-19 (Javafoodie TikTok Account Case Study)}

\begin{abstract}
During the Covid-19 pandemic, many culinary business actors experienced a decrease in business income, especially in tourist areas such as Yogyakarta. This makes culinary entrepreneurs look for solutions to keep earning income. One effort that can be done is to promote its products through social media. Currently the popular social media platform is Tiktok. The total Tiktok application downloads in 2020 were 63.3 million times and Indonesia became the country with the most downloads of the application, $11 \%$ of the total Tiktok application downloads. Based on these facts, the Tiktok application has the opportunity to become an effective promotional media in marketing the culinary industry, especially in the Special Region of Yogyakarta. One of the Tiktok accounts promoting the culinary industry in the Special Region of Yogyakarta is Javafoodie. The Javafoodie account promotes the culinary industry with a unique method, namely story telling with a comedic nuance, so that it is expected to attract consumer buying interest. The purpose of this study is to find out what factors make Tiktok an effective promotional media during the Covid-19 pandemic. Researchers draw the conclusion that Tiktok is an effective promotional media because Tiktok has many users, is easy to use, is popular with millennials, is often used by celebrities and has Tiktok ads features that can optimize content distribution.
\end{abstract}

Keywords: Social Media, Promotion, Tiktok

\section{PENDAHULUAN}

Tahun 2020 menjadi tahun dimana kita belajar untuk sudah membiasakan diri hidup di masa pandemic. Pandemi yang belum tahu kapan akan berakhir ini menjadikan semua pihak menyiapkan diri untuk tetap beraktivitas dengan tetap patuh pada protokol kesehatan 
yang sudah ditetapkan pemerintah. Semua segi kehidupan mengalami perubahan dari yang biasanya offline menjadi online. Masyarakat akhirnya sudah terbiasa menggunakan media online untuk memenuhi kebutuhannya.

Adanya dampak Covid-19 mengakibatkan selama tahun 2019 pemerintah menerapkan semua kegiatan dilakukan dirumah. Meskipun ada yang masih bisa mengerjakan pekerjaan dikantor tapi dengan cara berselang, dicombain antara WFO (Work For Office) dan WFH (Work For Home). Banyak aktivitas yang dilakukan diluar berkurang demi menjaga kesehatan dan keselamatan baik untuk diri sendiri maupun orang lain.

Banyaknya masyarakat yang berada dirumah membuat mereka mencari cara bagaimana agar tidak merasa jenuh dan bosan dirumah tetapi masih tetap berkreatifitas / bekerja. Salah satunya dengan bantuan teknologi internet. Penggunaan smartphone yang bisa mengakses dan menjalankan apapun dengan satu jari menjadi pilihan banyak orang.

Dilasir dari data bps.go.id diketahui pada tahun 2020 terdapat $92,85 \%$ penduduk kota Yogyakarta yang berumur 5 tahun keatas menggunakan telepon seluler (HP) atau computer (PC/Laptop/Notebook/Tablet) dan terdapat $83,42 \%$ penduduk kota Yogyakarta yang mengakses internet selama tahun 2020. Berdasarkan gambaran tersebut terlihat masyarakat cenderung bahkan tergantung pada internet. Internet memberikan banyak dampak positif salah satunya kita akan lebih mudah mendapatkan informasi tanpa terbatas tempat dan waktu.

Longgarnya kebijakan dari pemerintah terkait social distancing beberapa bulan di akhir tahun 2020 kemarin mengakibatkan banyak masyarakat yang mungkin sudah agak jenuh di rumah akhirnya bisa keluar rumah dengan tetap menggunakan dan menerapkan protokol kesehatan. Salah satu dampak diperbolehkannya masyarakat keluar rumah berimbas pada tempat wisata dan restoran. Banyak masyarakat yang sudah berani mendatangi tempat - tempat wisata dan mendatangi restoran sekedar makan, berkumpul dengan teman - teman atau keluarga dan sekedar refreshing. Kondisi tersebut membuka angin segar untuk tempat wisata dan restoran dengan tetap menyediakan sarana untuk menunjang protokol kesehatan seperti penyediaan tempat cuci tangan, sabun, hand sanitizer dan alat pengukur suhu tubuh. Industri kuliner juga harus membatasi jumlah pengunjung dan karyawan yang akhirnya dibagi dalam beberapa shift waktu.

Namun, kondisi tersebut masih juga membuat masyarakat masih takut dan mengurungkan diri untuk mendatangi tempat tempat tersebut karena memilih berdiam diri dirumah demi kesehatan dan keselamatan bersama. Kondisi itulah yang menjadikan pihak manajemen tempat wisata mapun restoran harus memutar otak untuk tetap dapat meningkatkan jumlah pemasukan di masa pandemi ini. Mereka harus bisa memasarkan produknya dan memberikan informasi tentang produknya sehingga masyarakat tahu dan tertarik untuk mendatanginya. Salah satu yang digunakan adalah dengan penggunaan media sosial. Salah satunya platform Tiktok.

Aplikasi tiktok di tahun 2020 berkembang pesat dan menjadi budaya baru di Indonesia. Meskipun aplikasi tersebut sudah ada sejak tahun 2018 namun belakangan ini aplikasi tersebut banyak digandrungi oleh masyarakat berbagai usia. Pada awal munculnya aplikasi tersebut sempat diblokir oleh Kementerian Komunikasi dan Informatika dengan alasan aplikasi tersebut memberikan dampak negatif untuk anak - anak. Setelah 2 tahun berlangsung aplikasi tik tok menjadi trend dan budaya baru buat masyarakat Indonesia (Utama dan Novina, 2018).

Banyak orang yang menggunakan aplikasi Tik tok untuk sekedar berkreativitas atau memberikan informasi mengenai suatu hal. Lewat video dan lagu / nyanyian yang ditampilkan diaplikasi ini memudahkan informasi dapat disampaikan dan dapat memberikan rangsangan untuk yang melihatnya, menirukan / menyebarkannya. Banyaknya masyarakat Indonesia terutama masyarakat Yogyakarta yang sudah banyak menggunakan internet menjadikan pangsa pasar yang menjanjikan untuk manajemen mempromosikan produknya / usahanya dengan menggunakan media sosial terutama tik tok.

Berdasarkan latar belakang tersebut maka peneliti ingin membuat penelitian terkait Pemanfaatan Media Sosial Tiktok Sebagai Media Promosi Industri Kuliner Di Yogyakarta Pada Masa Pandemi Covid-19.

\section{KAJIAN PUSTAKA}

Media sosial dapat diartikan sebagai media online yang menggunakan internet dimana para penggunanya dapat langsung berinteraksi, berpartisipasi dan berbagi isi / content nya. Menurut Kaplan dan Haenlein 
(2010) menyebutkan bahwa media sosial adalah layanan aplikasi berbasis internet yang mana konsumen dapat berbagi pendapat, sudut pandang, pemikiran dan pengalaman.

Media sosial dapat digunakan sebagai penghubung suatu informasi dan komunikasi dari seorang produsen ke konsumen. Konsumen bisa mendapatkan informasi sebuah produk dari media sosial begitu juga sebaliknya. Produsen dapat memenuhi kebutuhan informasi konsumen dengan menggunakan media sosial. Seperti yang dikemukakan oleh Merril (2011), menyebutkan bahwa media sosial menjadi media yang potensial untuk menemukan konsumen / pengguna produk dan membangun image merek produk. Media sosial merupakan salah satu system komunikasi yang memiliki fungsi : (1). Sebagai administrasi, (2). Media mendengarkan dan belajar, (3). Media berfikir dan melakukan perencanaan.

Keuntungan penggunaan media sosial dibanding media konvensional antara lain (a). sederhana : media sosial bersifat simple, mudah digunakan. Yang penting terhubung dengan internet maka media sosial dapat langsung digunakan oleh siapapun. (b). sebagai sarana relationship : media sosial dapat digunakan untuk membangun hubungan atau komunikasi dua arah karena dapat langsung dilakukan secara interaktif dan mendapatkan feedback satu sama lain. (c). memiliki jangkauan yang luas : media sosial memiliki jangkauan global, luas yang tidak dibatasi oleh waktu dan letak geografis. (d). bersifat terukur : menurut Wijaya (2013), menyebutkan bahwa media sosial system tracking nya / penelusurannya , pengiriman pesannya dapat terukur sehingga dapat diketahui efektifitas promosi yang dilakukan selain itu tidak memerlukan waktu yang lama.

Media sosial menghubungkan orang didunia untuk saling berhubungan satu sama lain. Seiring perkembangan pengaruh teknologi yang pesat dengan munculnya internet memunculkan berbagai aplikasi di media sosial yang memberikan peluang sebuah usaha (Augustinah dan Widayati, 2019). Saat ini sudah banyak usaha yang menggunakan media sosial untuk mempromosikan produk dan menjadikannya sebuah strategi bisnis.

Media sosial merubah sebuah komunikasi menjadi dialog interaktik yang mana satu sama lain bisa langsung berbagi informasi, pendapat, ide. Contoh media sosial antara lain : Facebook, Instagram, Youtube, Blog, Twitter, Messenger, WhatsApp dan masih banyak lagi. Dan sejak tahun 2018 muncullah aplikasi Tik tok yang digunakan sebagai sarana promosi yang dapat memberikan informasi yang tidak memerlukan biaya yang tinggi, tidak memerlukan tenaga yang banyak dan dapat dilakukan dalam waktu yang singkat.

Tik Tok menjadi salah satu platform yang sedang sangat digemari saat ini. Sebagai salah satu media sosial tik tok memberikan sarana berbagi konten yang sangat bervariasi dari segi kreativitas, video challenge, lipsync, lagu, menari, bernyanyi dan lain lain. Karena banyaknya yang menggunakan maka Tik Tok memberikan peluang sebagai sarana promosi.

Strategi marketing yang dapat dilakukan dengan platform Tik Tok antara lain: (a). menggunakan hashtag: hashtag (\#) sebuah tanda yang memiliki maksud agar suatu pokok bahasan, peristiwa, bahkan sebuah produk dapat mudah ditemukan. Dengan hashtag yang diberikan / digunakan dapat membantu konsumen mencari produk yang dicarinya/ dibutuhkannya. (b). mengikuti tren yang terjadi : strategi pemasaran dengan menggunakan Tik Tok mengandalkan video yang menggambarkan hal yang sedang tren. Untuk kondisi ini produsen harus dapat menemukan moment yang sesuai untuk produknya untuk dapat dipromosikan dan dikenalkan ke konsumen. (c). melakukan kolaborasi dengan para influencer : hal ini dapat dilakukan dengan melakukan kolaborasi dengan influencer yang sedang digemari dan memiliki banyak pengikut sehingga strategi promosi yang dilakukan lewat Tik Tok dapat memikat dan menarik banyak orang. Dengan catatan tujuan pasar yang ingin dituju jelas. (d). memberikan deskripsi yang jelas : seseorang akan tertarik pada sebuah video selain dari konten nya yang bagus juga terdapat deskripsi/info produk yang disampaikan jelas. Sehingga konsumen akan memahami konten yang disampaikan lebih jelas. (e). sering memposting video dan dapat disela dengan iklan.

Strategi ini dilakukan dengan melakukan upload/posting video secara rutin sehingga lebih banyak orang yang akan melihat / mengunjungi akun produk kita. Semakin banyak video yang diunggah maka membuka peluang konsumen untuk menonton dan jika sudah semakin banyak konten anda dilihat maka strategi yang lain adalah dapat diberikan iklan sehinggan promosi yang anda tawarkan dapat dilakukan dan ditargetkan.

Banyaknya pengguna smartphone menjadi peluang bagi para produsen untuk menggunakannya sebagai sarana promosi produk. Digital marketing adalah kegiatan 
promosi yang menggunakan media elektronik. Perkembangan teknologi dan media informasi berdampak juga terhadap promosi yang dilakukan. Dimana sudah beralih ke promosi online. Banyak pengusaha yang lebih memilih mempromosikan produk mereka dengan internet salah satunya dengan media sosial. Dengan keuntungan lebih murah, proses promosi cepat, jangkauannya luas dapat dilihat oleh seluruh dunia. Namun kekurangan promosi dengan penggunaan media internet ini antara lain : dibutuhkan kreativitas yang tinggi untuk dapat mempromosikan produknya karena banyaknya para pesaing / competitor.

\section{METODE PENELITIAN}

Objek penelitian dalam penelitian ini adalah pemanfaatan media sosial Tik tok sebagai media promosi yang dilakukan oleh Javafoodie dalam mendukung industri kuliner Yogyakarta. Nama pengguna akun tik tok adalah @javafoodie. Akun tiktok tersebut memiliki jumlah pengikut sebanyak 58.700. Untuk mengetahui aktivitas promosi yang dilakukan oleh akun tik tok javafoodie dan mengetahui faktor-faktor pembentuk media sosial Tik Tok sebagai media promosi yang efektif maka peneliti menggunakan paradigma konstruktivis. Paradigma konstruktivis bertujuan untuk memperoleh pengertian, rekonstruksi penelitian kualitatif sehingga ditemukan pengertian yang mendalam dari publik maupun individu. Metode penelitian yang digunakan peneliti adalah kualitatif deskriptif. Data yang digunakan diperoleh dari observasi dan wawancara.

\section{HASIL DAN PEMBAHASAN}

Saat ini media sosial menjadi salah satu media yang efektif dalam melakukan kegiatan promosi, dan salah satu media sosial yang sedang berkembang adalah Tik tok. Tik tok memiliki keuntungan dalam kegiatan promosi seperti memberikan informasi yang memadai tanpa biaya tinggi, tenaga banyak dan dapat dilakukan dalam waktu yang relatif singkat. Kegiatan promosi melalui media sosial meliputi iklan, promosi penjualan, pemasaran langsung, pemasaran personal dan public relation (Rangkuti, 2009). Kegiatan promosi yang dilakukan oleh akun tik tok javafoodie berupa public relation dengan menggunakan testimonial dan video informasi. Informasi yang diberikan disampaikan dengan narasi berupa cerita dan komedi. Hal tersebut merupakan karakter yang ingin disampaikan oleh akun javafoodie, yaitu memiliki karakter komedi, ceria dan menghibur. Karakter tersebut diharapkan dapat diterima dan dimiliki oleh followers atau viewers yang melihat setiap video dari akun javafoodie yang kebanyakan merupakan generasi milenial. Video-video yang telah diunggah dalam akun tiktok javafoodie secara konsisten membentuk karakter tersebut dengan menggunakan properti yang disukai anak muda dan juga keterangan video yang sederhana tapi memberikan informasi dan motivasi yang jelas. Unsur informasional dan emosinal terkandung dalam pesan dan informasi yang disampaikan oleh javafoodie melalui akun tiktoknya. Dalam video tersebut terdapat nama restoran atau brand dan juga keterangan harga produk yang dipromosikan sehingga memenuhi unsur informasional. Selain itu dalam video yang diunggah akun javafoodie mengandung unsur emosional karena berisikan pesan - pesan positif, yang dikemas dalam unsur komedi.

Pada setiap unggahan video akun javafoodie terdapat hashtag yang juga ikut disertakan. Tanda pagar yang diberikan adalah \#fyp, \#tiktokfoodie \#noodle \#foryourpage dan lain sebagainya. Tanda pagar \#fyp atau \#foryourpage digunakan agar unggahan video dari akun javafoodie dapat masuk kedalam halaman utama dari akun tiktok bukan followers akun javafoodie sehingga mereka tertarik dan menjadi followers akun javafoodie. Setidaknya menjadi viewers dan informasi yang diberikan melalui video tersebut dilihat dan tersampaikan dengan baik. Sedangkan tanda pagar \#tiktokfoodie \#noodle, \#steak atau tanda pagar lainnya yang berisi nama makanan bertujuan untuk memudahkan followers atau viewers dalam menemukan video unggahan yang diberikan oleh javafoodie sesuai dengan kategori yang dicari. Akun javafoodie sampai saat ini memiliki jumlah followers sebanyak 61.200 dan jumlah likes sebanyak 1.900.000. Pada periode penelitian ini dilakukan yaitu pada September 2020 sampai dengan Januari 2021, konten yang memiliki Jumlah likes tertinggi berjudul "Mari saling membantu" yang mempromosikan warung makan Babakaran street dengan jumlah likes sebanyak 30.200. Sedangkan jumlah likes terendah sebanyak 53 likes, terdapat pada konten berjudul "Brownies Crispy" yang mempromosikan produk dari merek lemonilo berupa camilan brownies crispy.

Menurut hootsuite.com, pada tahun 2019 aplikasi Tiktok sudah diunduh sebanyak 1,65 miliar kali dan telah terpasang pada gawai elektronik sebanyak 738 juta kali. Hal tersebut memberikan petunjuk bahwa Tiktok 
menjadi aplikasi media sosial yang populer dan berkembang. Perkembangan aplikasi Tiktok menjadi kesempatan bagi para pengusaha atau para pelaku pemasaran untuk melakukan personal branding atau mempromosikan produknya.

Adapun alasan menggunakan media sosial Tiktok sebagai media promosi yang efektif adalah:

(1) Tiktok memiliki banyak user. Menurut Pertiwi (2020), pada Agustus 2020 aplikasi Tiktok dinobatkan sebagai aplikasi terlaris dengan jumlah unduhan sebesar 63,3 juta baik di apple store maupun play store. Indonesia menjadi negara yang paling banyak mengunduh aplikasi tersebut sebesar $11 \%$ dari total unduhan aplikasi Tiktok.

\begin{tabular}{|c|c|c|}
\hline Top Apps Worldwide for & t 2020 by Downloads ( $\mathrm{N}$ & (D) Sensortower \\
\hline Overall Downloads & App Store Downloads & Google Play Downloads \\
\hline $1 \boldsymbol{J ~ T i k T o k}$ & 1 J TikTok & 1 d TikTok \\
\hline $2 \square Z O O M$ & $20 \mathrm{ZOOM}$ & 20 Snack Video \\
\hline 3 ff Facebook & 3 - YouTube & 3 ff Facebook \\
\hline 4 (0) Instagram & 4 (0) Instagram & 4 Google Meet \\
\hline 5 (9) WhatsApp & 5 (Q) WhatsApp & $5 \mathrm{COOOM}$ \\
\hline 6 Google Meet & 6 ff Facebook & 6 (0) Instagram \\
\hline 70 Snack Video & 7 Messenger & 7 WhatsApp \\
\hline 8 Messenger & $8 M$ Gmail & 8 Messenger \\
\hline $9 \&$ Snapchat & 9 Google Maps & 9 \& Snapchat \\
\hline 10 (3) Telegram & ${ }_{10} \mathbb{N}$ Netflix & 10 (1) MX TakaTak \\
\hline
\end{tabular}

Sumber : www.kompas.com

Gambar 1. Data Aplikasi dengan jumlah unduhan tertinggi di seluruh dunia pada Agustus 2020.

Berdasarkan data tersebut mengindikasikan bahwa Tiktok merupakan media sosial dengan jumlah user yang banyak dan diminati, maka mempromosikan produk dengan menggunakan media tersebut memungkinkan untuk terlihat oleh banyak users dan memiliki potensi untuk memotivasi minat beli konsumen.

(2) Aplikasi Tiktok merupakan salah satu media sosial yang mudah digunakan. Menurut Hasiholan,dkk (2020), aplikasi Tiktok memiliki antar muka yang mudah dan user friendly. Aplikasi Tiktok memungkinkan pengguna untuk menentukan menambahkan efek khusus seperti slow motion, beauty effect, green screen, transisi, stiker, teks, GIF, emoji dan efek lainnya. Selain itu users dapat menentukan antarmuka musik yang sesuai dengan dengan keinginannya setelah itu memungkinkan users untuk membuat video pendek sesuai kreatifitas dan musik favorit mereka. Aplikasi Tiktok juga menyediakan beberapa perangkat yang memudahkan penggunanya seperti timer, start dan stop record, dan lain sebagainya.
(3) Aplikasi Tiktok merupakan salah satu media sosial yang banyak dimiliki oleh pengguna generasi milenial, generasi $Y$ dan $Z$. Rakhmayanti (2020), mengatakan bahwa generasi $Y$ dan $Z$ usia antara 14 sampai dengan 24 tahun mendominasi pengguna Tiktok di Indonesia. Generasi tersebut merupakan merupakan generasi yang sering melakukan belanja secara online sehingga lebih konsumtif dan impulsif. Maka dari itu Tiktok dapat menjadi media sosial yang efektif dalam melakukan promosi produk.

(4) Merupakan media sosial yang sering digunakan oleh selebriti. Menurut Hasiholan, dkk (2020) saat ini semakin banyak selebriti di Indonesia menggunakan Tiktok sebagai media untuk melakukan eksistensi publik, sehingga membuat masyarakat Indonesia mengikuti trend tersebut. Banyak sekali selebriti yang mengunggah video kreasi mereka melalui akun Tiktok dan melakukan posting ulang ke akun sosial media lainnya yang mereka miliki. Dengan begitu, melalui fenomena ini semakin banyak pengguna aplikasi Tiktok, sehingga berdampak pada semakin luas pasar yang dapat diraih dari pemasaran melalui media sosial Tiktok.

(5) Fitur Tiktok ads. Aplikasi Tiktok memiliki fitur iklan yang dapat digunakan untuk mengoptimalkan penyebaran konten yang dibuat. Pada fitur tersebut pengguna dapat menetapkan tujuan pembuatan iklan, menetapkan anggaran dan target iklan, melakukan unggahan video, dan menambahkan fitur Call To Action (CTA) iklan. Fitur CTA dapat mengarahkan viewers menuju website, media sosial lainnya, melakukan tindakan pembelian dan hal lainnya sesuai dengan tujuan yang ingin dicapai oleh pengguna.

Pandemi Covid-19 yang melanda dunia dan dirasakan oleh semua negara berdampak pada menurunnya pendapatan yang diterima oleh para pelaku usaha kuliner khususnya di Daerah Istimewa Yogyakarta. Penurunan pendapatan para pelaku usaha restoran dapat terlihat pada menurunnya penerimaan pajak restoran Pemkot Yogyakarta yang semula $R p$ 4,6 miliar pada tahun 2019 menjadi 2,6 miliar pada tahun 2020 (Yanuar, dan Widhia 2020). Hal tersebut diakibatkan berlakuknya kebijakan PSBB (Pembatasan Sosial Berskala Besar) yang dikeluarkan oleh Pemerintah. Untuk membangkitkan promosi destinasi wisata Kementerian Pariwisata dan Ekonomi Kreatif (Kemenparekraf) melakukan promosi pariwisata melalui media sosial dan salah satu media sosial yang digunakan adalah Tiktok. Menurut data dari Kemenparekraf, sekitar 73,7 
persen masyarakat Indonesia menggunakan internet untuk membuka bermacam-macam platform media sosial. Maka dari itu media sosial dapat menjadi saluran komunikasi yang baik untuk mempromosikan potensi wisata Indonesia termasuk Industri kuliner.

Salah satu akun tiktok yang terus mempromosikan industri kuliner di Yogyakarta adalah akun tiktok Javafoodie. Javafoodie mempromosikan industri kuliner dengan menggunakan metode story telling sehingga membuat isi pesan tersampaikan dengan baik kepada viewers video yang diunggah oleh akun Javafoodie.

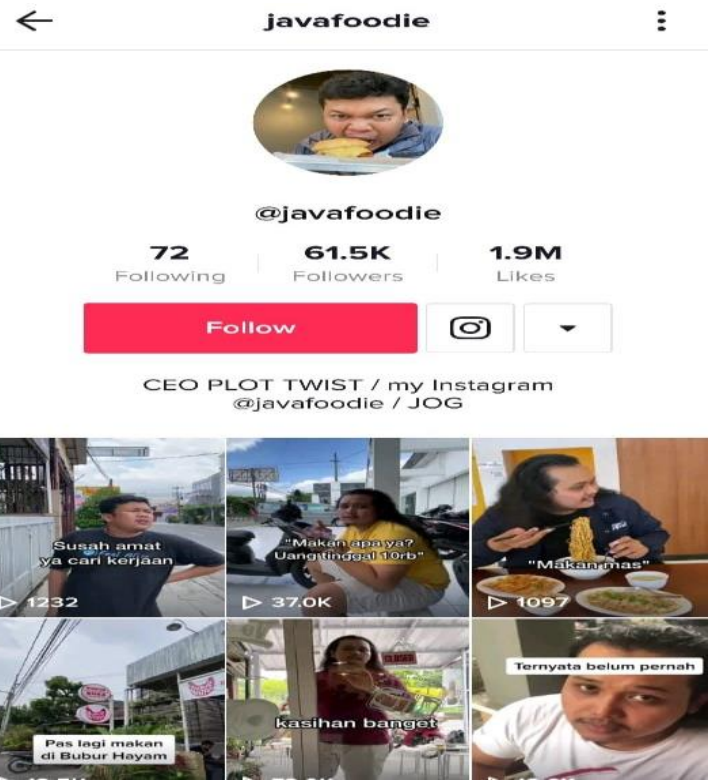

Sumber : Akun Tiktok Javafoodie.

Gambar 2. Akun Tiktok Javafoodie

Melalui gambar diatas dapat terlihat tampilan akun Javafoodie dengan isi foto profil, nama ID akun, jumlah following, jumlah followers dan jumlah total likes yang dimiliki oleh akun Javafoodie dari semua unggahan video akun tersebut di aplikasi Tiktok. Akun Tiktok Javafoodie juga memiliki link ke media sosial instagram yang dimiliki oleh Javafoodie. Konten yang diunggah oleh Javafoodie berupa video singkat berupa story telling yang mempromosikan makanan dari beberapa pelaku usaha kuliner di Daerah Istimewa Yogyakarta.

Pengguna Tiktok di Indonesia yang ratarata merupakan generasi millenial memiliki minat lebih menonton video promosi kuliner yang dikemas dengan metode story telling bernuansa komedi tanpa ada unsur pemaksaan dalam video tersebut. Sebagai contoh pada akun tiktok javafoodie dengan konten video berjudul "tips agar warungmu rame" membangun promosi produk kuliner dimsum mentai dari warung makan /se-ling-an/ dengan cerita menarik yang dibalur komedi diikuti dengan tulisan yang memberikan informasi dan juga memiliki background music yang sedang trend di Tiktok, dimana pada video ini sudah dilihat oleh 74.200 pengguna, disukai sebanyak 10.300 pengguna, dan di share sebanytak 138 kali.

Perkembangan penggunaan aplikasi Tiktok yang begitu pesat di Indonesia, dapat menjadikan Tiktok sebagai media promosi yang efektif dalam meningkatkan industri kuliner di Indonesia, terutama di Daerah Istimewa Yogyakarta pada masa pandemi Covid-19. Hal ini dikarenakan media sosial Tiktok dapat menjangkau masyarakat luas, dengan sekitar $64 \%$ masyarakat Indonesia merupakan pengguna internet dan kurang lebih 160 juta penduduk Indonesia adalah pengguna aktif sosial media (Hasiholan dkk, 2020).

\section{PENUTUP}

Teknologi canggih yang digunakan oleh pengembang aplikasi Tiktok menyajikan pola algoritma proses yang berbeda dari media sosial lainnya. Pengguna disajikan video yang cocok dengan kebutuhan dan minat pengguna secara tepat. Selain itu pengguna diberikan kebebasan untuk melakukan share video yang mereka lihat di Tiktok dengan berbagai cara dan mudah dilakukan. Tiktok menjadi media pemasaran yang efektif karena Indonesia merupakan pengguna aplikasi Tiktok terbesar di dunia, aplikasi Tiktok mudah digunakan, aplikasi Tiktok merupakan salah satu media sosial yang banyak dimiliki oleh pengguna generasi milenial, generasi $\mathrm{Y}$ dan $\mathrm{Z}$, aplikasi Tiktok banyak digunakan oleh selebriti, sehingga masyarakat mengikuti idolanya, dan fitur Tiktok ads yang unik dan dapat menjangkau pasar lebih luas.

Tiktok merupakan media yang ideal dalam mempromosikan industri kuliner di Daerah Istimewa Yogyakarta. Akun Tiktok Javafoodie menjadi salah satu akun Tiktok di Yogyakarta yang mempromosikan beragam Kuliner khas Yogyakarta. Video-video yang diunggah oleh akun Javafoodie mempromosikan kuliner Yogyakarta yang menarik dikemas dengan metode story telling bernuansa komedi. Akun Tiktok Javafoodie merupakan salah satu akun Tiktok yang mempromosikan kuliner Yogyakarta, dan masih banyak lagi akun Tiktok lainnya yang bergerak untuk mempromosikan kuliner Yogyakarta. PSBB atau Pembatasan Sosial Berskala Besar akibat pandemi Covid-19 menjadi keterbatasan peneliti dalam 
memperoleh. Data penelitian akan lebih komprehensif jika diperoleh melalui observasi, wawancara langsung atau dengan penyebaran kuesioner terhadap pelaku usaha atau end user industri kuliner di Yogyakarta. Maka dari itu saran untuk penelitian selanjutnya dapat melakukan penelitian kuantitatif untuk memperoleh data secara komprehensif dan dapat mengukur tingkat pengaruh media sosial Tiktok terhadap penjualan restoran. Diharapkan dengan adanya promosi melalui media sosial Tiktok ini dapat meningkatkan pendapatan dari peaku usaha kuliner di Daerah Istimewa Yogyakarta pada masa pandemi Covid-19 ini.

\section{DAFTAR PUSTAKA}

Augustinah, F dan Widayati. 2019. Pemanfaatan Media Sosial Sebagai Sarana Promosi Makanan Ringan Kripik Singkong Di Kabupaten Sampang. Jurnal Dialektika, Volume 4, Nomor 2 September 2019.

Hasiholan, dkk. 2020. Pemanfaatan Media Sosial Tik Tok Sebagai Media Kampanye Gerakan Cuci Tangan Di Indonesia Untuk Pencegahan Corona Covid-19. Communiverse : Jurnal IImu Komunikasi, Volume 5 No. 3 Juni 2020.

Kaplan, .M dan Haenlein, M. 2010. Users of the world, Unite! The Challenges and Opportunities of Social Media. Business Horizons.

Merril, T., Latham, K. Santalesa R, Navetta, D.2011. Social Media : The Business Benefit May Be Enermous, But Can The Risks Reputation, Legal,
Operational Bemitigated Information Law Group.

Pertiwi, Wahyunanda Kusuma. 2020. Indonesia Sumbang Angka Unduhan TikTok Terbanyak di Dunia. https://tekno.kompas.com/read/2020/0 9/11/15010037/indonesia-sumbangangka-unduhan-tiktok-terbanyak-didunia (diakses pada tanggal 16 September 2020)

Rakhmayanti, Intan. 2020. Pengguna TikTok di Indonesia Didominasi Generasi $Z$ dan Y

https://tekno.sindonews.com/berita/15 23692/207/pengguna-tiktok-diindonesia-didominasi-generasi-z-dan-y (diakses pada tanggal 15 September 2020).

Rangkuti, F. 2009. Strategi Promosi yang Kreatif dan Analisis Kasus Integrated Marketing Communication. Jakarta: PT. Gramedia Pustaka Utama.

Utama, Lazuardhi dan Novina P.B. 2018. Ini Penyebab Kominfo Putuskan Blokir TikTok. https://www.viva.co.id/digital/digilife/10 50527-ini-penyebab-kominfoputuskan-blokir-tik-tok (diakses pada tanggal 16 September 2020).

Yanuar, Regi dan Widhia Dinnata 2020. Pendapatan Daerah Kota Jogja Diprediksi Tergerus Rp 330 Miliar. https://ayoyogya.com/read/2020/05/04/ 39294/pendapatan-daerah-kota-jogjadiprediksi-tergerus-rp330-miliar (diakses pada tanggal 16 September 2020). 